\title{
Young people's recall and perceptions of gambling advertising and intentions to gamble on sport
}

\author{
CHRISTIAN NYEMCSOK ${ }^{1}$, SAMANTHA L. THOMAS ${ }^{1}$, AMY BESTMAN ${ }^{1}$, HANNAH PITT $^{1}$, \\ MIKE DAUBE ${ }^{2}$ and REBECCA CASSIDY ${ }^{3}$ \\ ${ }^{1}$ Centre for Population Health Research, School of Health and Social Development, Faculty of Health, \\ Deakin University, Burwood, VIC, Australia \\ ${ }^{2}$ Faculty of Health Sciences, Curtin University, Bentley, WA, Australia \\ ${ }^{3}$ Department of Anthropology, Goldsmiths, University of London, London, UK
}

(Received: August 13, 2018; revised manuscript received: November 15, 2018; accepted: November 22, 2018)

\begin{abstract}
Background: There has been an increased international policy focus on the factors that may contribute to, and prevent, the normalization of gambling for young people. However, there is still limited research, which investigates the role of advertising in shaping young people's gambling attitudes and consumption intentions. Methods: Mixed methods study of 111 young people aged 11-16 years recruited from community basketball stadiums in Victoria, Australia, between May and July 2018. Interviewer-assisted surveys investigated recall and awareness of sports betting brands, perceptions of promotional strategies, intention to gamble, and reasons for betting on particular sports. Quantitative data were analyzed using descriptive statistics and $\chi^{2}$ tests. Thematic analyses were used to interpret qualitative responses. Results: Young people had high recall and awareness of advertising, with most able to name at least one betting brand ( $n=90,81.1 \%$ ), and many demonstrating a high awareness of the distinct characteristics (such as colors and appeal strategies) of different brands. A fifth of young people $(n=25,22.5 \%)$ expressed intentions to gamble at 18 years, with boys significantly more likely than girls to state they would gamble $\left(\chi^{2}=10.90, p=.001\right)$. Young people perceived that advertising strategies associated with inducement promotions would be the most influential in encouraging individuals to gamble. While many young people took promotions at face value, there was evidence that some were able to critically engage with and challenge the messages within marketing. Discussion and conclusions: Current regulatory structures appear to be ineffective in limiting young people's recall and awareness of gambling advertising. Lessons from tobacco control support the application of precautionary approaches as a more effective way to limit young people's development of positive gambling attitudes and behaviors.
\end{abstract}

Keywords: gambling, advertising, children, brand recall, television, sport

\section{BACKGROUND}

There is an increasing research focus on the factors that may contribute to the normalization of gambling, including factors that may shape positive attitudes toward gambling products and gambling participation (Thomas, Pitt, et al., 2018). In a rapidly changing gambling environment, with the development of new, easily accessible products, and the alignment of these products with major sporting codes, research has shifted from addiction-based models that seek to understand individual vulnerability factors, toward public health frameworks that seek to understand the influence, and interplay of a broader range of determinants that may shape pathways to gambling (Bestman, Thomas, Randle, Pitt, \& Daube, 2018; Pitt, Thomas, Bestman, Stoneham, \& Daube, 2016). For example, researchers have demonstrated the impact of the alignment of gambling with major sporting codes on the normalization of gambling in the peer groups of young male sports fans (Deans, Thomas, Daube, \& Derevensky, 2016) and the impact of promotional tactics on their gambling behaviors (Deans, Thomas, Derevensky, \& Daube, 2017).

Most recently, researchers have sought to understand factors that may contribute to the normalization of gambling in children and young people ( $\mathrm{Li}$, Langham, Browne, Rockloff, \& Thorne, 2018; McMullan, Miller, \& Perrier, 2012), and in particular, those who are fans of sport (Hing, Vitartas, Lamont, \& Fink, 2014; Pitt, Thomas, Bestman, Stoneham, et al., 2016). Although gambling is illegal prior to the age of 18 years in several countries, studies have investigated that young people engage in formal or informal gambling prior to the legal age (Gambling Commission, 2017; Rossen et al., 2016) and may experience harms at a higher rate than adults (Fröberg et al., 2015;

* Corresponding author: Samantha L. Thomas; Centre for Population Health Research, School of Health and Social Development, Faculty of Health, Deakin University, 221 Burwood Highway, Burwood, VIC 3125, Australia; Phone: +61 3924 45453; E-mail: Samantha.thomas@deakin.edu.au

This is an open-access article distributed under the terms of the Creative Commons Attribution-NonCommercial 4.0 International License, which permits unrestricted use, distribution, and reproduction in any medium for non-commercial purposes, provided the original author and source are credited, a link to the CC License is provided, and changes - if any - are indicated. 
Gambling Commission, 2017; Rossen et al., 2016). For example, research in Australia indicates that between $60 \%$ and $80 \%$ of young people will have gambled formally (e.g., on lotteries) or informally (e.g., on card games with friends or sweeps) at least once in the previous year (Delfabbro, King, \& Griffiths, 2014; Purdie et al., 2011). Research from the UK suggests that about $12 \%$ of $11-16$ year olds participated in gambling in the previous year, most commonly on fruit machines, which have no age restriction in the UK (4\%), and private bets $(3 \%)$, with boys twice as likely to report doing so as girls (Gambling Commission, 2017). The most recent prevalence study of youth gambling in Canada found that approximately $41 \%$ of young people aged 13-19 years had gambled in the past 3 months, with those engaging in online gambling slightly more vulnerable to problem gambling (Elton-Marshall, Leatherdale, \& Turner, 2016). Researchers have suggested that young people are additionally vulnerable to gambling harm, because they may misunderstand the risks and probability of success and loss involved with gambling (Defoe, Dubas, Figner, \& van Aken, 2015; Ferland, Ladouceur, \& Vitaro, 2002). This is an important point, given new marketing environments for gambling, which researchers argue may create a perception among young people that gambling is associated with limited risk (Pitt, Thomas, Bestman, Stoneham, et al., 2016).

The importance of exploring the process of normalization and the impact of the alignment between gambling companies (and their promotions) and sport are highlighted by the lessons learnt from other public health areas. Researchers have drawn upon tobacco control research, which demonstrated the impact of marketing in positively shaping or normalizing the attitudes of young people toward cigarettes, and contributing to their subsequent consumption of, and preference for, tobacco products (Lovato, Watts, \& Stead, 2011; Pechmann \& Knight, 2002). For example, research highlighted that the promotion of cigarettes, particularly aligned with sport, had a powerful influence on young people's ability to recall the brand names of tobacco products, and in shaping their choice of cigarette brands (Aitken \& Eadie, 1990; Pollay et al., 1996).

While research in relation to gambling marketing and young people's gambling behavior is still in its early stages, researchers have proposed that some of the strategies used within gambling advertising, including the use of voice-overs, music, catchy slogans, humor, and celebrities, may have particular appeal for young people, and may contribute to their recall of particular gambling brands (Pitt, Thomas, Bestman, Randle, \& Daube, 2018; Sklar \& Derevensky, 2010). For example, studies have demonstrated that young people who are highly engaged as "fans" of major sporting codes are able to recall specific features of advisements, such as storylines and distinctive voiceovers, can link promotional strategies with the correct brands (Pitt, Thomas, Bestman, Daube, \& Derevensky, 2017b; Pitt, Thomas, Bestman, Stoneham, et al., 2016), and align gambling sponsors with correct sporting codes and teams (Thomas et al., 2016). However, there has been limited research to identify the types of promotions that young people perceive would be most influential in encouraging individuals to gamble, or in encouraging them to gamble with specific companies.
Researchers have also demonstrated the impact of gambling advertising on young people's technical knowledge of sports betting. A study by Pitt et al. (2017b) found that despite having never gambled, some young people displayed technical knowledge of sports betting, including being able to discuss and describe "odds," different gambling markets, and how to place bets, predominantly because of the marketing they had seen. While research has demonstrated that young people increasingly perceive that gambling is a socially and culturally accepted and endorsed part of the sporting experience (Pitt, Thomas, Bestman, Daube, \& Derevensky, 2017a; Pitt, Thomas, Bestman, Stoneham, et al., 2016; Sproston, Hanley, Brook, Hing, \& Gainsbury, 2015), few studies have sought to understand whether or not young people are able to critically engage with the marketing that they see. Furthermore, to our knowledge, few studies have investigated the factors that may influence them to gamble on different sports.

The following study was conducted with 11-16 year olds in Victoria, Australia. This study aimed to explore young people's awareness and recall of sports betting brands, their perception of the influence of marketing messages aligned with sport, and their ability to engage critically with the information that they see about sports betting. The study was guided by the following research questions:

1. To what extent do young people demonstrate recall and awareness of sports betting brands? Are there specific promotional appeal strategies that they recall more than others?

2. Which types of promotional strategies do young people consider the most influential in encouraging people to gamble?

3. Is there evidence that young people intend to gamble when they are older? What, if anything, might influence their decision to gamble with specific brands?

4. Is there any evidence that young people are critically engaging with the marketing they see for gambling, or feel negatively toward gambling?

\section{METHODS}

\section{Approach}

This paper was part of a broader study investigating young people's attitudes toward gambling promotions in sport. A further paper from this study explores young people's awareness of the placement and timing of gambling advertising, and provides extensive detail about the methods for the study (Thomas, Bestman, et al., 2018).

On April 1, 2018, the Australian Federal Government implemented regulations intended to limit young people's exposure to gambling advertising within sport. Televised gambling advertising within live sport was prohibited from $5 \mathrm{~min}$ before the start of the game, until $5 \mathrm{~min}$ after the game, up to 8.30 p.m. (Australian Communication and Media Authority, 2018). For the purposes of this study, it is important to note that the half time breaks in night broadcasts of Australian Football League (AFL) matches (the major sporting code in Australia) often take place at or around 8.30 p.m. 
Outside live sport, gambling advertising is regulated between 6 a.m. and 8:30 a.m., and 4 p.m. and 7 p.m. on G-rated (and below) channels, and between 5 a.m. and 8:30 p.m. during programs aimed primarily at children (Australian Communication and Media Authority, 2015). There are no regulations relating to sponsorship promotions, including at sporting grounds, and on team uniforms, and limited rules relating to social media advertising, such as YouTube or Snapchat. There are also significant gaps in regulations associated with television advertising, including exemptions for subscription sports television channels with a minor audience share (who do not have to comply with the advertising ban in live sport before 8:30 p.m.); commentary in the lead up to the start of live sporting matches; and advertising within sports and current affairs (news) programs, such as sports commentary programs, which often inhabit time slots prior to the 7:30 p.m. watershed (Thomas, Bestman, et al., 2018).

\section{Sampling and recruitment}

The study used a range of convenience and purposive sampling techniques to recruit young people at three community basketball stadiums in Victoria, Australia. The age range for the study, 11-16 years, was chosen, given research suggesting that this is when young people become aware of the marketing of brands, and are able to understand the persuasive intent of marketing they observe (Hudson \& Elliott, 2013). The study focused on young people who participated in basketball. This group was selected for two reasons. First, American National Basketball Association (NBA) games in 2018 were played on a subscription channel in Australia, which was exempt from gambling advertising restrictions (Australian Communication and Media Authority, 2018; McIver, 2018). Second, previous studies have recruited young people who were fans of Australia's two major sporting codes, the AFL and the National Rugby League (NRL; Pitt et al., 2017a; Pitt, Thomas, Bestman, Stoneham, et al., 2016). Therefore, there is limited knowledge about young people who were fans of sports outside of these two major sporting codes, their consumption of media for these sports, and their recall and awareness of gambling advertising. The sample did not aim to be representative (and thus generalizable) to all young people in Victoria, but aimed to complement existing research with young people who were fans of sporting codes other than the AFL and NRL.

Young people were recruited over seven data collection periods (May-July 2018). This time period coincided with the 2018 NBA playoffs and finals series. Up to five researchers visited the stadiums, where parents/carers and young people were approached by a member of the research team to provide information about the study and invite participation. Written consent (parents/carers) and verbal consent (young people) were given by participants prior to participation. Young people received a non-branded drink bottle as a token of appreciation. Purposive sampling was used to diversify the sample. For example, we specifically focused on recruiting girls to the study, given that previous research had predominantly focused on boys (Pitt et al., 2017b; Thomas et al., 2016).

\section{Data collection}

Interviewer-assisted, mixed method surveys (composed of discrete choice and open ended questions) were completed on a digital device using the Qualtrics software offline application, and took 10-12 min to complete. The following sections relate to the data analyzed as part of this paper.

General characteristics. We collected information about age, gender, and sports participation, as well as information about the type of basketball code (local, national, and international) most watched on different media platforms.

Brand recall and awareness. This section aimed to assess young people's recall and awareness of sports betting brands. Similar to other studies, young people were asked to name all gambling brands they could remember, with researchers moving to the next question when young people were struggling to think of any or further brands. No prompting was given. We recorded the first brand recalled (top of mind recall), and all subsequent brands recalled. Young people were then asked to qualitatively describe the advertising in open-ended questions that they had seen for the first brand they had recalled. To compare depth of awareness of the characteristics associated with different brands, young people were read the names of six sports betting brands and asked to name the color that they most associated with that brand. They were then shown six de-branded images of gambling promotions, and asked to identify the brand that they most associated with that image. Young people were asked not to guess answers and only to provide answers if they believed that they were confident of the correct answer.

Influence of promotional strategies. Young people were shown six images of different strategies used in sports betting promotions. This included a call to bet now, a bonus bet offer, a cash out promotion, an image of a celebrity within a gambling promotion, a money back offer, and a sign-up offer. Young people were then asked to select the promotion they thought would be most influential in encouraging someone to gamble, and to give reasons for their selection.

Intentions to gamble. Young people were asked if they would bet on sport after they turned 18 years old as a yes/no question. All young people were asked if they were to bet on any sport, which sport would they bet on and why. Young people were then asked to qualitatively describe the factors that may lead them to gamble with a particular company or brand.

\section{Data analysis}

Data were uploaded to Statistical Package for the Social Sciences (SPSS, USA) from Qualtrics for analysis. Data were cleaned, with minor adjustments made to minor typographical and wording issues relating to the input of the qualitative data.

For brand awareness, basic descriptive statistics were used to calculate the percentage of young people that recalled specific brands. Chi-squared tests for independence $\left(\chi^{2}\right)$ were conducted to determine differences between categorical variables for age and gender, and the recall and awareness of brands. To analyze differences between age 
and brand recall, the sample was categorized into two age groups: $11-12$ years $(n=55,49.5 \%)$ and $13-16$ years $(n=56,50.5 \%)$. For the brand color association task and de-branded advertisements task, percentages were calculated based on the total sample of young people who provided an answer for these questions (given that young people were asked not to guess the answer). For the color awareness task, each brand was allocated a dominant color, with answers marked as correct if young people specifically mentioned this color, even if they mentioned another color as well as this color (e.g., if the dominant brand color was blue, and the young person mentioned blue and white, this was categorized as a correct answer).

Qualitative responses were transferred to data management software QSR NVivo 11. A constant comparative approach to thematic analysis was used to examine similarities and differences particularly according to gender (Charmaz, 2006). Regular meetings were held between the authors to discuss emerging themes from the data, with discussions about the key findings and data interpretations.

\section{Ethics}

Ethical approval was received by the University Human Research Ethics Committee (2018-087).

\section{RESULTS}

\section{General, sporting, and media characteristics}

The general, sporting, and media characteristics of the sample are presented in Table 1. A total of 111 young people aged $11-16$ years $(M=12.9, S D=1.5)$ participated in the study. While the majority of the sample were boys $(n=66,59.5 \%)$, the number of girls $(n=45$, $40.5 \%$ ) in the study were roughly similar to the percentage of girls participating in basketball in the state of Victoria (SportsTG, 2018). Almost all young people played basketball $(n=108,97.3 \%)$, and about a quarter also played for a local AFL team $(n=26,23.4 \%)$. The American NBA was the most watched basketball code $(n=87,78.4 \%)$, followed by the Australian National Basketball League $(n=74$, $66.7 \%)$. Subscription television ( $n=47,42.3 \%)$, free to air television $(n=36,32.4 \%)$, and YouTube $(n=26,23.4 \%)$ were the most common platforms used for media viewing of basketball.

\section{Sports betting brand recall}

Young people's recall of sports betting brands is presented in Table 2. The majority of young people recalled at least one gambling brand, including sports betting brands, online bookmakers, and/or lottery providers $(n=94$, $84.6 \%$ ). Over three-quarters of young people recalled at least one sports betting brand $(n=90,81.1 \%$, range: $0-5$, $M=1.5, S D=1.1)$. Boys were significantly more likely to recall at least one sports betting brand, compared to girls $\left(\chi^{2}=4.90, p=.027\right)$. Sportsbet was the brand with the highest top of mind recall ( $n=51,45.9 \%)$, as well as being the most frequently recalled $(n=64,57.7 \%)$, followed by the TAB $(n=14,12.6 \%)$ and Ladbrokes $(n=14,12.6 \%)$. Boys were significantly more likely to recall Ladbrokes $\left(\chi^{2}=14.17, p=.00\right)$ and $\operatorname{Bet} 365\left(\chi^{2}=7.49, p=.006\right)$, compared to girls.

Table 1. General, sporting, and media characteristics

\begin{tabular}{|c|c|c|c|c|c|}
\hline & \multicolumn{2}{|c|}{ Gender } & \multicolumn{2}{|c|}{ Age } & \multirow[b]{2}{*}{$\begin{array}{c}\text { Total } \\
(n=111)\end{array}$} \\
\hline & $\begin{array}{c}\text { Male } \\
n=66(59.5 \%)\end{array}$ & $\begin{array}{c}\text { Female } \\
n=45(40.5 \%)\end{array}$ & $\begin{array}{c}11-12 \\
n=55(49.5 \%)\end{array}$ & $\begin{array}{c}13-16 \\
n=56(50.5 \%)\end{array}$ & \\
\hline \multicolumn{6}{|c|}{ Sport played $-n(\%)^{\mathrm{a}}$} \\
\hline Basketball & $66(100.0 \%)^{*}$ & $42(93.3 \%)^{*}$ & $53(96.4 \%)$ & $55(98.2 \%)$ & $108(97.3 \%)$ \\
\hline AFL & $20(30.3 \%)^{*}$ & $6(13.3 \%)^{*}$ & $14(25.5 \%)$ & $12(21.4 \%)$ & $26(23.4 \%)$ \\
\hline Other & $5(7.6 \%)^{*}$ & $11(24.4 \%)^{*}$ & $14(25.5 \%)^{* *}$ & $2(3.6 \%)^{* *}$ & $16(14.4 \%)$ \\
\hline \multicolumn{6}{|c|}{ Type of basketball watched $-n(\%)^{\mathrm{a}}$} \\
\hline Any basketball & $65(98.5 \%)^{*}$ & $38(84.1 \%)^{*}$ & $50(90.9 \%)$ & $53(94.6 \%)$ & $103(92.8 \%)$ \\
\hline NBA & $56(84.8 \%)^{*}$ & $31(68.9 \%)^{*}$ & $43(78.2 \%)$ & $44(78.6 \%)$ & $87(78.4 \%)$ \\
\hline NBL & $50(75.8 \%)^{*}$ & $24(53.3 \%)^{*}$ & $36(65.5 \%)$ & $38(67.9 \%)$ & $74(66.7 \%)$ \\
\hline College & $14(21.2 \%)^{*}$ & $3(6.7 \%)^{*}$ & $0^{* *}$ & $17(30.4 \%)^{* *}$ & $17(15.3 \%)$ \\
\hline Other & $14(21.2 \%)$ & $14(31.1 \%)$ & $11(20.0 \%)$ & $17(30.4 \%)^{* *}$ & $28(25.2 \%)$ \\
\hline \multicolumn{6}{|c|}{ Basketball viewing (media and live platforms) $-n(\%)^{\mathrm{a}}$} \\
\hline Subscription TV & $30(45.5 \%)$ & $17(37.8 \%)$ & $25(45.5 \%)$ & $22(39.3 \%)$ & $47(42.3 \%)$ \\
\hline Free to air TV & $18(27.3 \%)$ & $18(40.0 \%)$ & $21(38.2 \%)$ & $15(26.8 \%)$ & $36(32.4 \%)$ \\
\hline YouTube & $17(25.8 \%)$ & $9(20.0 \%)$ & $12(21.8 \%)$ & $14(25.0 \%)$ & $26(23.4 \%)$ \\
\hline Websites & $16(24.2 \%)^{*}$ & $1(2.2 \%)^{*}$ & $4(7.3 \%)^{* *}$ & $13(23.2 \%)^{* *}$ & $17(15.3 \%)$ \\
\hline NBA league ${ }^{b}$ & $9(13.6 \%)^{*}$ & $1(2.2 \%)^{*}$ & $4(7.3 \%)$ & $6(10.7 \%)$ & $10(9.0 \%)$ \\
\hline Go to game & $5(7.6 \%)$ & $3(6.7 \%)$ & $3(5.5 \%)$ & $5(8.9 \%)$ & $8(7.2 \%)$ \\
\hline Other & $6(9.1 \%)$ & $2(4.4 \%)$ & $4(7.3 \%)$ & $4(7.1 \%)$ & $8(7.2 \%)$ \\
\hline
\end{tabular}

Note. $n$ : number of participants; \%: column percentages; AFL: Australian Football League; NBA: National Basketball Association; NBL: National Basketball League.

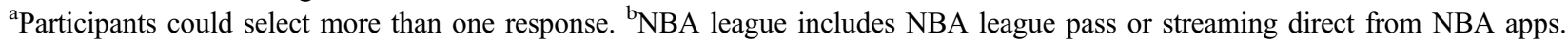

*Significance between genders at 0.05 . ${ }^{*}$ Significance between age groups at 0.05 . 
Table 2. Sports betting brand recall

\begin{tabular}{|c|c|c|c|c|c|}
\hline & \multicolumn{2}{|c|}{ Gender } & \multicolumn{2}{|c|}{ Age } & \multirow{2}{*}{$\begin{array}{c}\text { Total } \\
(n=111)\end{array}$} \\
\hline & Male $(n=66)$ & Female $(n=45)$ & $11-12(n=55)$ & $13-16(n=56)$ & \\
\hline \multicolumn{6}{|c|}{ Overall number of sports betting brands recalled } \\
\hline 0 & $8(12.1 \%)$ & $13(28.9 \%)$ & $14(25.5 \%)$ & $7(12.5 \%)$ & $21(18.9 \%)$ \\
\hline 1 & $20(30.3 \%)$ & $23(51.1 \%)$ & $18(32.7 \%)$ & $25(44.6 \%)$ & $43(38.7 \%)$ \\
\hline $2+$ & $38(57.6 \%)$ & $9(20.0 \%)$ & $23(41.8 \%)$ & $24(42.9 \%)$ & $47(42.3 \%)$ \\
\hline \multicolumn{6}{|c|}{ Top of mind brand recalled } \\
\hline Sportsbet & $31(47.0 \%)$ & $20(44.4 \%)$ & $25(45.5 \%)$ & $26(46.4 \%)$ & $51(45.9 \%)$ \\
\hline TAB & $6(9.1 \%)$ & $8(17.8 \%)$ & $5(9.1 \%)$ & $9(16.1 \%)$ & $14(12.6 \%)$ \\
\hline Ladbrokes & $13(19.7 \%)$ & $1(2.2 \%)$ & $5(9.1 \%)$ & $9(16.1 \%)$ & $14(12.6 \%)$ \\
\hline Bet365 & $3(4.5 \%)$ & 0 & $2(3.6 \%)$ & $1(1.8 \%)$ & $3(2.7 \%)$ \\
\hline Crownbet & $1(1.5 \%)$ & $2(4.4 \%)$ & $3(5.5 \%)$ & 0 & $3(2.7 \%)$ \\
\hline Neds & $2(3.0 \%)$ & $1(2.2 \%)$ & $1(1.8 \%)$ & $2(3.6 \%)$ & $3(2.7 \%)$ \\
\hline Unibet & $2(3.0 \%)$ & 0 & 0 & $2(3.6 \%)$ & $2(1.8 \%)$ \\
\hline None & $8(12.1 \%)$ & $13(28.9 \%)$ & $14(25.5 \%)$ & $7(12.5 \%)$ & $21(18.9 \%)$ \\
\hline \multicolumn{6}{|c|}{ Overall brand recall ${ }^{\mathrm{a}}$} \\
\hline Sportsbet & $42(63.6 \%)$ & $22(48.9 \%)$ & $31(56.4 \%)$ & $33(58.9 \%)$ & $64(57.7 \%)$ \\
\hline TAB & $18(27.3 \%)$ & $10(22.2 \%)$ & $11(20.0 \%)$ & $17(30.4 \%)$ & $28(25.2 \%)$ \\
\hline Ladbrokes & $23(34.8 \%)^{*}$ & $2(4.4 \%)^{*}$ & $9(16.4 \%)$ & $16(28.6 \%)$ & $25(22.5 \%)$ \\
\hline Crownbet & $13(19.7 \%)$ & $6(13.3 \%)$ & $13(23.6 \%)$ & $6(10.7 \%)$ & $19(17.1 \%)$ \\
\hline Bet365 & $10(15.2 \%)^{*}$ & $0^{*}$ & $4(7.3 \%)$ & $6(10.7 \%)$ & $10(9.0 \%)$ \\
\hline Neds & $5(7.6 \%)$ & $2(4.4 \%)$ & $3(5.5 \%)$ & $4(7.1 \%)$ & $7(6.3 \%)$ \\
\hline Unibet & $3(4.5 \%)$ & 0 & 0 & $3(5.4 \%)$ & $3(2.7 \%)$ \\
\hline Ubet & $2(3.0 \%)$ & 0 & $1(1.8 \%)$ & $1(1.8 \%)$ & $2(1.8 \%)$ \\
\hline William Hill & $2(3.0 \%)$ & 0 & $1(1.8 \%)$ & $1(1.8 \%)$ & $2(1.8 \%)$ \\
\hline Other & $2(3.0 \%)$ & 0 & 0 & $2(3.6 \%)$ & $2(1.8 \%)$ \\
\hline
\end{tabular}

Note. $n$ : number of participants; \%: column percentages.

${ }^{a}$ Participants could select more than one response.

*Significance between genders at 0.05 .

\section{Sports betting brand awareness}

Table 3 presents results relating to brand awareness. The majority of young people associated the dominant brand color with at least one brand ( $n=102,91.9 \%$, range: $0-5$, $M=2.0, S D=1.3)$, and just over a third $(n=40,36.0 \%)$ correctly associated the dominant brand color with three or more brands. Boys were significantly more likely to associate the dominant color with at least one brand as compared to girls $\left(\chi^{2}=6.37, p=.041\right)$. Most young people were able to correctly identify the sports betting brand associated with at least one promotion $(n=81,73.0 \%$, range: $0-4, M=1.5, S D=1.3$ ), with just under a quarter correctly identifying the brands for three or more advertisements $(n=26,23.4 \%)$.

\section{Brand attributes and appeal strategies}

When asked to describe the advertising they had seen for the brand they most recalled, young people described a number of distinct attributes and appeal strategies.

First were the deal-based promotions that young people perceived would directly contribute to individuals winning money. While both boys and girls recalled a range of promotions that would directly help to "win your bet," "double your winnings," or help to win specific amounts

Table 3. Sports betting brand awareness

\begin{tabular}{|c|c|c|c|c|c|}
\hline & \multicolumn{2}{|c|}{ Gender } & \multicolumn{2}{|c|}{ Age } & \multirow{2}{*}{$\begin{array}{c}\text { Total } \\
(n=111)\end{array}$} \\
\hline & Male $(n=66)$ & Female $(n=45)$ & $11-12(n=55)$ & $13-16(n=56)$ & \\
\hline \multicolumn{6}{|c|}{ Number of dominant brand colors correctly associated with brands } \\
\hline 0 & $5(7.6 \%)$ & $4(8.9 \%)$ & $5(9.1 \%)$ & $4(7.1 \%)$ & $9(8.1 \%)$ \\
\hline $1-2$ & $31(47.0 \%)$ & $31(68.9 \%)$ & $31(56.4 \%)$ & $31(55.4 \%)$ & $62(55.9 \%)$ \\
\hline 3 or more & $30(45.5 \%)$ & $10(22.2 \%)$ & $19(34.5 \%)$ & $21(37.5 \%)$ & $40(36.0 \%)$ \\
\hline \multicolumn{6}{|c|}{ Number of brands identified with the correct promotion } \\
\hline 0 & $17(25.8 \%)$ & $13(28.9 \%)$ & $16(29.1 \%)$ & $14(25.0 \%)$ & $30(27.0 \%)$ \\
\hline $1-2$ & $29(43.9 \%)$ & $26(57.8 \%)$ & $25(45.5 \%)$ & $30(53.6 \%)$ & $55(49.5 \%)$ \\
\hline 3 or more & $20(30.3 \%)$ & $6(13.3 \%)$ & $14(25.5 \%)$ & $12(21.4 \%)$ & $26(23.4 \%)$ \\
\hline
\end{tabular}

Note. $n$ : number of participants; \%: column percentages. 
of money with specific bets, boys described deal-based promotions in much more detail. For example, some girls only described the outcome of deals "if you win you will get heaps of money", whereas boys provided specific technical information about these deals. A few boys described winning money associated with specific sporting achievements, including the first point scorer, "\$50 if your team scores the first point," or if a team led by a specific number of points or goals:

"They convince you to double your money. Put a little in and it doubles. Double in footy every time you score a goal." - 12-year-old boy.

Second were those who were aware of money back promotions that young people perceived reduced the risk of losing money. Some young people specifically recalled deals that were linked with cash back inducements, including promotions that guaranteed individuals would get their money back after placing a bet, "get 50 bucks back" or "get your money back." Young people perceived that these types of deals would ensure that "you can get out" if losing money, or would assure you that you would not lose money if you gambled:

"They tell you to spend money on it and they say you have guaranteed money back. So it's trying to reassure that you won't lose, and it's on in every ad break." 13-year-old girl.

Third, young people described the plotlines and distinctive voice-overs associated with sports betting advertisements. In particular, young people were able to associate particular strategies with particular brands, and describe how these strategies distinguished one brand from another. For example, young people were able to describe the actors, and the specific types of betting markets that particular brands were promoting:

"The new Sportsbet one on the TV is a guy holding a vase. And when a guy shouts, he drops when vase, and says to bet on Saturday's multi." - 12-year-old boy.

A few young people were able to differentiate between brands because of the distinctive voice-overs associated with brands. For example, some said they remembered
Sportsbet because of loud or funny voices. When describing what they recalled from Ladbrokes, a few young people stated that these advertisements "always have someone with an accent," with one girl specifically identifying a British or Cockney accent:

"Some guy rambling about the odds. Ladbrokes is different. Has a British guy talking." - 16-year-old girl.

However, in their descriptions of the brand they had first recalled, some young people critically reflected on the strategies that were used. In particular, young people challenged the notion that gambling led to financial gain or winning, commenting that these outcomes were "not really going to happen" or "not true, all fake." Others observed that advertising overinflated people's perceptions of financial outcomes by "mak(ing) you think you can win $\$ 1$ million." One boy particularly described in detail how advertising for gambling emphasized that it was easy to win money, with no emphasis on the negative impacts of gambling:

"They always try to make it look easy to win. No negatives about betting, it's all about the positives. They show the odds and how much money to put on." 14-year-old boy.

\section{Influence of promotional strategies}

Table 4 presents the results relating to promotions that young people thought would be the most influential in encouraging an individual to gamble. Inducement promotions were the top two promotional strategies selected, including money back offers $(n=47,42.3 \%)$ and sign-up offers $(n=20,18.0 \%)$. Some young people perceived that these specific deals meant that there was significantly less risk involved in losing money after the outcome of the bet, describing that particular promotions could allow an individual to "get your money back," or meant that a gambler would be "unlikely to get ripped off." Some stated that money back offers were less risky because "you could lose some but not lose all of it. It's not as big a risk."

However, while many young people interpreted the meaning of the promotions at face value, some participants, and particularly boys, viewed these promotions with a more

Table 4. Most influential promotional strategies in encouraging individuals to gamble

\begin{tabular}{|c|c|c|c|c|c|}
\hline \multirow{2}{*}{$\begin{array}{l}\text { Individual responses for } \\
\text { each promotion }\end{array}$} & \multicolumn{2}{|c|}{ Gender } & \multicolumn{2}{|c|}{ Age } & \multirow{2}{*}{$\begin{array}{c}\text { Total } \\
(n=111)\end{array}$} \\
\hline & Male $(n=66)$ & Female $(n=45)$ & $11-12(n=55)$ & $13-16(n=56)$ & \\
\hline Money back & $29(43.9 \%)$ & $18(40.0 \%)$ & $19(34.5 \%)$ & $28(50.0 \%)$ & $47(42.3 \%)$ \\
\hline Sign-up offer & $8(12.1 \%)$ & $12(26.7 \%)$ & $13(23.6 \%)$ & $7(12.5 \%)$ & $20(18.0 \%)$ \\
\hline Celebrity endorsement & $10(15.2 \%)$ & $5(11.1 \%)$ & $5(9.1 \%)$ & $10(17.9 \%)$ & $15(13.5 \%)$ \\
\hline Bonus bet & $7(10.6 \%)$ & $6(13.3 \%)$ & $6(10.9 \%)$ & $7(12.5 \%)$ & $13(11.7 \%)$ \\
\hline Cash out & $8(12.1 \%)$ & $3(6.7 \%)$ & $9(16.4 \%)$ & $2(3.6 \%)$ & $11(9.9 \%)$ \\
\hline Bet now & $1(1.5 \%)$ & 0 & 0 & $1(1.8 \%)$ & $1(0.9 \%)$ \\
\hline None & $3(4.5 \%)$ & $1(2.2 \%)$ & $3(5.5 \%)$ & $1(1.8 \%)$ & $4(3.6 \%)$ \\
\hline
\end{tabular}

Note. $n$ : number of participants; \%: column percentages. 
Table 5. Intentions to gamble

\begin{tabular}{|c|c|c|c|c|c|}
\hline & \multicolumn{2}{|c|}{ Gender } & \multicolumn{2}{|c|}{ Age } & \multirow{2}{*}{$\begin{array}{c}\text { Total } \\
(n=111)\end{array}$} \\
\hline & Male $(n=66)$ & Female $(n=45)$ & $11-12(n=55)$ & $13-16(n=56)$ & \\
\hline \multicolumn{6}{|c|}{ Intention to gamble at 18 years old } \\
\hline Yes & $22(33.3 \%)$ & $3(6.7 \%)$ & $9(16.4 \%)$ & $16(28.6 \%)$ & $25(22.5 \%)$ \\
\hline No & $44(66.7 \%)$ & $42(93.3 \%)$ & $46(83.6 \%)$ & $40(71.4 \%)$ & $86(77.5 \%)$ \\
\hline \multicolumn{6}{|c|}{ Sports they would bet on ${ }^{\mathrm{a}}$} \\
\hline AFL & $33(50.0 \%)$ & $24(53.3 \%)$ & $29(52.7 \%)$ & $28(50.0 \%)$ & $57(51.4 \%)$ \\
\hline Basketball & $34(51.5 \%)$ & $15(33.3 \%)$ & $26(47.3 \%)$ & $23(41.1 \%)$ & $49(44.1 \%)$ \\
\hline Horseracing & $9(13.6 \%)$ & $5(11.1 \%)$ & $4(7.3 \%)$ & $10(17.9 \%)$ & $14(12.6 \%)$ \\
\hline Other & $1(1.5 \%)$ & $2(4.4 \%)$ & $2(3.6 \%)$ & $1(1.8 \%)$ & $3(2.7 \%)$ \\
\hline None & $2(3.0 \%)$ & $3(6.7 \%)$ & $4(7.3 \%)$ & $1(1.8 \%)$ & $5(4.5 \%)$ \\
\hline
\end{tabular}

Note. $n$ : number of participants; \%: column percentages.

${ }^{\text {a }}$ Participants could select more than one response.

critical lens. Young people commented that these types of promotions could make people think that gambling was less risky for individuals, "it seems safe but it really isn't," or could "trick people" into thinking they would not lose their money "sucks people in so they think they aren't losing money." One girl was particularly critical of sign-up offers, describing how people may accept this type of promotion at face value and misunderstand the associated risks:

"People think ah yeah, you get this back for it, and don't understand risk behind it." - 12-year-old girl.

\section{Intentions to gamble}

Table 5 presents results relating to young people's intentions to gamble. A fifth of young people $(n=25,22.5 \%)$ said that they thought they would bet on sport when they were 18 years old. Boys were significantly more likely to indicate they would bet when they were 18 compared to girls $\left(\chi^{2}=\right.$ $10.90, p=.001)$. Three-quarters of young people $(n=86$, $77.5 \%)$ stated that they would not bet on sport when they were 18 years old, with more girls $(n=42,93.3 \%)$ indicating this than boys $(n=44,66.7 \%)$. Girls were more likely to either use moral justifications for not engaging in gambling, stating that "I don't agree with it" or "don't think it's right," or state that they would rather spend their money on things that they valued, 'I'd rather spend my money on something important." However, most young people attributed financial loss associated with betting on sport, stating that "it's a waste of money" and that "most people lose more money than they make." Young people also perceived gambling to be a risky activity "I think it's too risky" that could lead to addiction.

When asked which sport they would bet on (whether they thought they would bet when they were older or not), most stated that they would bet on the AFL $(n=57,51.4 \%)$ or some form of basketball $(n=49,44.1 \%)$. Most young people stated that they chose this sport in particular, because they were knowledgeable about the sport. This included that they knew the teams, "I know the teams well," or the technical statistics associated with the sport "I know which teams are going to get through and the statistics for them." In particular, one young girl described how her knowledge of sport meant that she had a better chance of winning:
"Because I know it. That would be my only best chance of choosing. I've got more experience so I'll have more of a chance." - 13-year-old girl.

Others chose a particular sport, because they watched it more frequently, or because they were passionate about it. Some chose particular sports that involved only two teams, because they perceived that this would improve the chances of winning: "there's only two teams so there is more of a chance."

When asked about the range of reasons that may influence someone to gamble with certain betting companies, young people's responses were all associated with the advertising that they had seen. Young people stated that they would choose a particular brand because they had seen the advertising for that brand and were familiar with it; they liked the advertisements they had seen for that brand, or advertisements that promoted the best deals or offers:

\section{"Sportsbet, because if you bet with them you can get your money back." - 11-year-old boy.}

\section{DISCUSSION}

This study aimed to explore young people's awareness and recall of sports betting brands, their perception of the influence of marketing messages aligned with sport, and their ability to engage critically with the information that they see about sports betting. The study, which is the first to be conducted on this issue since the implementation of new advertising regulations in Australia, raises four points for discussion.

First, young people in this study had high spontaneous recall of sports betting brands, and most also demonstrated depth of recall across a number of brands. Most young people in this study were able to recall the names of sports betting brands, describe what they remembered was distinctive about the advertising they had seen for these brands, distinguish the dominant colors associated with different brands, and correctly match brand names with promotions. This is an important finding given that research from 
tobacco has demonstrated a link between young people's awareness of marketing and their receptivity toward smoking (Braun et al., 2015). Furthermore, initial exposure to promotions for cigarettes, recall and awareness of messages about cigarettes in everyday environments, and having positive attitudes toward specific brands (DiFranza et al., 2006; Evans, Farkas, Gilpin, Berry, \& Pierce, 1995; Pierce, Choi, Gilpin, Farkas, \& Berry, 1998) have all been found to be central to the uptake of smoking. As well as recalling subtle cues in advertisements, such as brand name, color, packaging (Petty \& Cacioppo, 1986), and recalling tobacco company brand names in the context of engaging with product marketing (Aitken \& Eadie, 1990; Smith \& Swinyard, 1988).

Second, while one in five young people in this study did not recall any gambling brands, the majority of young people in this research had high recall and awareness of inducement marketing strategies that might reduce their perception of the relative risks of gambling. Even young people who were not able to directly recall brand names were still able to describe the strategies used in gambling advertising. These findings reinforce preliminary research, which has shown that inducement-based advertising, such as cashback offers, may create perceptions that people do not lose money from gambling (Pitt et al., 2017b; Pitt, Thomas, Bestman, Stoneham, et al., 2016). Young people also selected these types of inducement promotions as the most influential in encouraging people to gamble. This is an important finding as previous research has shown that young people perceived that celebrity endorsement of gambling was one of the most influential mechanisms in creating trust in products (Pitt, Thomas, \& Bestman, 2016). To date, and with the exception of sign-up offers (Toscano, 2017), limited attention has been paid to the range of inducement promotions that are advertised through various media platforms, and the impact that they may have on young people. It is clear from our findings that restrictions must go further in limiting the depiction of inducements that may create a perception that the risks of gambling can be reduced, particularly because the majority of the young people questioned in this study appear to take these promotions at face value.

Third, this study shows that one fifth of young people, and significantly more boys than girls, would like to try gambling when they reach the legal age of 18 years. This is an important finding given that Thomas, Pitt, et al. (2018) argue that "trying rates" are a specific dimension associated with the normalization of gambling. In designing strategies to counter this normalization pathway, it is important to understand the range of factors that may be stimulating current or intended engagement in gambling. This is the first study to our knowledge that has investigated the range of factors young people think would influence them to gamble with a specific brand, with familiarity and deals both identified as influential. Research from both tobacco and alcohol suggest that young people's preferences for tobacco and alcohol brands are influenced by their familiarity with brands, stemming from their exposure and engagement with brand marketing (Grant, Hassan, Hastings, MacKintosh, \& Eadie, 2008; Saffer, 2002), with brand familiarity considered more influential than peer influence on young people's smoking uptake (Saffer, 2002).

Fourth, this study showed that some young people were critical about the marketing that they saw, and most stated that they did not want to gamble when they were older. Most of this criticism related to the perceptions of risks associated with gambling, particularly to losing money. However, these attitudinal responses do not necessarily mean that these young people are immune from the influences of marketing. Research from tobacco has shown that even though young people held negative attitudes toward smoking, intrinsic cues that are designed to generate interest in tobacco products, such as the appearance of cigarettes and the color, size, and imagery of cigarette packaging, had significant appeal for them (Ford, Moodie, MacKintosh, \& Hastings, 2013; Meier, 1991). Further investigation of how marketing interacts with other determinants (such as peer influence) and affects perceptions of risk is necessary, particularly given evidence that marketing may reduce young people's perceptions of the risks associated with gambling (McMullan et al., 2012).

Some have suggested that an appropriate precautionary response would be to ensure that "responsible gambling" or help seeking messages are displayed alongside gambling promotions (Wigmore, 2018), with some Australian campaigns encouraging parents to talk to children about gambling (Victorian Responsible Gambling Foundation, 2018). Applying the concept of "logic based on parallel evidence," we would argue there is little evidence to support the effectiveness of such approaches (McKinsey Global Institute, 2014, p. 41). Research in the fields of tobacco and alcohol has shown clearly that in order to be effective, campaigns must be sustained, research-based, and sit within a broader comprehensive approach, which includes strict regulation, curbs on availability and accessibility of products, and tight controls on promotions (National Preventative Health Taskforce, 2009).

If gambling products are harmful in themselves, then restrictions on advertising are necessary (Orford, 2010). The logical and most effective precautionary response would be to ensure that gambling promotions are significantly restricted across multiple media platforms to decrease young people's exposure and familiarity with these products. Italy has already embraced this approach, banning all gambling advertising, except for the National Lottery, from January 1, 2019 (Kelly, 2018). The Spanish Government is also considering legislation that would extend the restrictions to gambling, which currently apply to tobacco advertising (Arora, 2018).

\section{Limitations}

It is important to acknowledge the limitations of this study. First, the study collected data on a small convenience sample of young people in Victoria, and may not be generalizable to the broader population. Although the study aimed to include a diverse range of young people, the findings presented in this paper did not examine individual demographics except for gender. Second, while the study focused on young people who were engaged with basketball, it is unclear how general sports viewing may influence 
attitudes toward and recall of sports betting brands. Third, findings in this study are specific to the promotions used; therefore, the use of alternative materials may produce different results. Finally, this study only included young people up to the age of 16 years. Further research should investigate whether attitudes toward gambling change as young people transition to the legal age of gambling, and should explore the range of factors that may influence attitudinal changes.

\section{CONCLUSIONS}

This study shows that the current regulatory structures in Australia appear to be ineffective in preventing young people's recall and awareness of gambling brands and provides further evidence that a range of significant restrictions may be required to prevent young people's exposure to gambling advertising. This study has also explored potential synergies between tobacco and gambling research. While there are clear differences found between tobacco and gambling, there are also several similarities. Valuable insights about the regulation of gambling advertising can be gleaned from tobacco control, particularly as it relates to young people. This study also showed that young people who are engaged with sport are beginning to critically engage with gambling advertising. This development, and whether or not it extends beyond young fans of basketball, could provide an important focus for research in the future.

Funding sources: This study was funded via a research support account held by SLT.

Authors' contribution: CN contributed to the study design, data analysis, initial drafting, and critical revisions of the paper. SLT conceptualized study and contributed to study design, data collection and analysis, drafting the paper, and providing critical revisions of the paper. $\mathrm{AB}$ and HP contributed to study design, data collection and analysis, drafting the paper, and providing critical revisions of the paper. MD contributed to the drafting and critical revisions of the paper. RC contributed to study design, data analysis, drafting the paper, and providing critical revisions of the paper.

Conflict of interest: SLT has received funding in the past 3 years for gambling research from the Australian Research Council and the Victorian Responsible Gambling Foundation (which is funded via hypothecated taxes from gambling). She has also received consultancy funding for gambling harm prevention education from the AFL Players Association and AFL Sportsready. She has received travel funding for conference presentations from the Living Room Cardiff and the European Union. $\mathrm{AB}$ has received funding in the past 3 years for gambling research from the Victorian Responsible Gambling Foundation and an Australian Government Research Training Program scholarship. HP and MD have received funding in the past 3 years for gambling research from the Victorian Responsible
Gambling Foundation and the Australian Research Council. $\mathrm{RC}$ has received travel expenses in the past 3 years from Edinburgh University and the Graduate School for Humanities, University of Cologne. She has also received travel expenses from government departments and organizations, which derive their funding from government departments (including through hypothecated taxes on gambling), including the University of Helsinki Centre for Research on Addiction, Control and Governance; the Alberta Gambling Research Institute; the New Zealand Ministry of Health; the New Zealand Problem Gambling Foundation, and The Gambling and Addictions Research Centre at Auckland University of Technology. She has also received funding to organize and run a conference from the British Academy. She has paid to attend industry-sponsored events and attended free, industry-supported events in order to conduct anthropological fieldwork.

Acknowledgements: The authors would like to thank the basketball associations who agreed to let us collect data at the stadiums, and to local councils for their support of the project. They would also like to thank Ms. Simone McCarthy for assistance with data collection. Most importantly, they would like to thank the young people who participated in this project.

\section{REFERENCES}

Aitken, P. P., \& Eadie, D. R. (1990). Reinforcing effects of cigarette advertising on under-age smoking. British Journal of Addiction, 85(3), 399-412. doi:10.1111/j.1360-0443.1990. tb00657.x

Arora, A. (2018). Spanish government set to impose restrictions on gambling advertisements. Retrieved from https://pokerfuse. com/news/industry/210123-spanish-government-set-imposerestrictions-gambling/

Australian Communication and Media Authority. (2015). Commercial television code of practice. Retrieved from http://www. acma.gov.au/Industry/Broadcast/Television/TV-contentregulation/commercial-television-code-of-practice-tv-contentregulation-i-acma

Australian Communication and Media Authority. (2018). New gambling advertising rules during live sports. Retrieved from https://www.acma.gov.au/Industry/Broadcast/Television/ Advertising/new-gambling-advertising-rules-during-live-sports

Bestman, A., Thomas, S. L., Randle, M., Pitt, H., \& Daube, M. (2018). Exploring children's experiences in community gambling venues: A qualitative study with children aged 6-16 in regional New South Wales. Health Promotion Journal of Australia. Advance online publication. doi:10.1002/hpja.211

Braun, S., Kollath-Cattano, C., Barrientos, I., Mejía, R., Morello, P., Sargent, J. D., \& Thrasher, J. F. (2015). Assessing tobacco marketing receptivity among youth: Integrating point of sale marketing, cigarette package branding and branded merchandise. Tobacco Control, 25(6), 648-655. doi:10.1136/tobaccocontrol-2015-052498

Charmaz, K. (2006). Constructing grounded theory: A practical guide through qualitative analysis. Introducing Qualitative Methods Series. London, UK: Sage Publications. 
Deans, E. G., Thomas, S. L., Daube, M., \& Derevensky, J. (2016). The role of peer influences on the normalisation of sports wagering: A qualitative study of Australian men. Addiction Research \& Theory, 25(2), 103-113. doi:10.1080/16066359. 2016.1205042

Deans, E. G., Thomas, S. L., Derevensky, J., \& Daube, M. (2017). The influence of marketing on the sports betting attitudes and consumption behaviours of young men: Implications for harm reduction and prevention strategies. Harm Reduction Journal, 14(1), 5. doi:10.1186/s12954-017-0131-8

Defoe, I. N., Dubas, J. S., Figner, B., \& van Aken, M. A. (2015). A meta-analysis on age differences in risky decision making: Adolescents versus children and adults. Psychological Bulletin, 141(1), 48-84. doi:10.1037/a0038088

Delfabbro, P., King, D., \& Griffiths, M. D. (2014). From adolescent to adult gambling: An analysis of longitudinal gambling patterns in South Australia. Journal of Gambling Studies, 30(3), 547-563. doi:10.1007/s10899-013-9384-7

DiFranza, J. R., Wellman, R. J., Sargent, J. D., Weitzman, M., Hipple, B. J., \& Winickoff, J. P. (2006). Tobacco promotion and the initiation of tobacco use: Assessing the evidence for causality. Pediatrics, 117(6), e1237-e1248. doi:10.1542/peds. 2005-1817

Elton-Marshall, T., Leatherdale, S. T., \& Turner, N. E. (2016). An examination of Internet and land-based gambling among adolescents in three Canadian provinces: Results from the youth gambling survey (YGS). BMC Public Health, 16(1), 277. doi:10.1186/s12889-016-2933-0

Evans, N., Farkas, A., Gilpin, E., Berry, C., \& Pierce, J. P. (1995). Influence of tobacco marketing and exposure to smokers on adolescent susceptibility to smoking. Journal of the National Cancer Institute, 87(20), 1538-1545. doi:10.1093/jnci/87.20. 1538

Ferland, F., Ladouceur, R., \& Vitaro, F. (2002). Prevention of problem gambling: Modifying misconceptions and increasing knowledge. Journal of Gambling Studies, 18(1), 19-29. doi:10.1023/A:1014528128578

Ford, A., Moodie, C., MacKintosh, A. M., \& Hastings, G. (2013). Adolescent perceptions of cigarette appearance. The European Journal of Public Health, 24(3), 464-468. doi:10.1093/eurpub/ ckt161

Fröberg, F., Rosendahl, I. K., Abbott, M., Romild, U., Tengström, A., \& Hallqvist, J. (2015). The incidence of problem gambling in a representative cohort of Swedish female and male 16-24 year-olds by socio-demographic characteristics, in comparison with 25-44 year-olds. Journal of Gambling Studies, 31(3), 621-641. doi:10.1007/s10899014-9450-9

Gambling Commission. (2017). Young people and gambling 2017: A research study among 11-16 year olds in Great Britain. Retrieved from http://www.gamblingcommission.gov. uk/PDF/survey-data/Young-People-and-Gambling-2017-Report. pdf

Grant, I. C., Hassan, L. M., Hastings, G. B., MacKintosh, A. M., \& Eadie, D. (2008). The influence of branding on adolescent smoking behaviour: Exploring the mediating role of image and attitudes. International Journal of Nonprofit and Voluntary Sector Marketing, 13(3), 275-285. doi:10.1002/nvsm.329

Hing, N., Vitartas, P., Lamont, M., \& Fink, E. (2014). Adolescent exposure to gambling promotions during televised sport: An exploratory study of links with gambling intentions.
International Gambling Studies, 14(3), 374-393. doi:10.1080/ 14459795.2014.902489

Hudson, S., \& Elliott, C. (2013). Measuring the impact of product placement on children using digital brand integration. Journal of Food Products Marketing, 19(3), 176-200. doi:10.1080/ 10454446.2013.724370

Kelly, T. (2018, July 6). Italy bans advertising on all forms of gambling as part of new 'dignity decree' after populist 5-Star leader said betting destorys families. Daily Mail. Retrieved from https://www.dailymail.co.uk/news/article-5921655/Italy-bansgambling-adverts-Luigi-Di-Maios-new-dignity-decree.html

Li, E., Langham, E., Browne, M., Rockloff, M., \& Thorne, H. (2018). Gambling and sport: Implicit association and explicit intention among underage youth. Journal of Gambling Studies, 34(3), 739-756. doi:10.1007/s10899-018-9756-0

Lovato, C., Watts, A., \& Stead, L. F. (2011). Impact of tobacco advertising and promotion on increasing adolescent smoking behaviours. The Cochrane Database of Systematic Reviews, 10, CD003439. doi:10.1002/14651858.CD003439

McIver, D. (2018, May 23). NBA play-offs coverage reveals gap in gambling ad restrictions targeting kids. ABC News. Retrieved from http://www.abc.net.au/news/2018-05-08/nbaplay-offs-coverage-reveals-sports-betting-ad-loophole/9736060

McKinsey Global Institute. (2014). Overcoming obesity: An initial economic analysis. Retrieved from https://www.mckinsey. $\mathrm{com} / \sim /$ media/McKinsey/Business\%20Functions/Economic $\%$ 20Studies\%20TEMP/Our\%20Insights/How\%20the\%20world $\% 20$ could\%20better\%20fight\%20obesity/MGI_Overcoming obesity_Executive_summary.ashx

McMullan, J. L., Miller, D. E., \& Perrier, D. C. (2012). “I've seen them so much they are just there": Exploring young people's perceptions of gambling in advertising. International Journal of Mental Health and Addiction, 10(6), 829-848. doi:10.1007/ s11469-012-9379-0

Meier, K. S. (1991). Tobacco truths: The impact of role models on children's attitudes toward smoking. Health Education Quarterly, 18(2), 173-182. doi:10.1177/109019819101800203

National Preventative Health Taskforce. (2009). Australia: The healthiest country by 2020. National Preventative Health Strategy - The roadmap for action. Retrieved from https:// extranet.who.int/nutrition/gina/sites/default/files/AUS\%202009 $\% 20$ National $\% 20$ Preventative $\% 20$ Health $\% 20$ Strategy.pdf

Orford, J. (2010). An unsafe bet? The dangerous rise of gambling and the debate we should be having. Chichester, UK/Malden, MA: John Wiley \& Sons.

Pechmann, C., \& Knight, S. J. (2002). An experimental investigation of the joint effects of advertising and peers on adolescents' beliefs and intentions about cigarette consumption. Journal of Consumer Research, 29(1), 5-19. doi:10.1086/339918

Petty, R. E., \& Cacioppo, J. T. (1986). The elaboration likelihood model of persuasion. Advances in Experimental Psychology, 19, 123-205. doi:10.1016/S0065-2601(08)60214-2

Pierce, J., Choi, W., Gilpin, E., Farkas, A., \& Berry, C. (1998). Tobacco industry promotion of cigarettes and adolescent smoking. Journal of the American Medical Association, 279(7), 511-515. doi:10.1001/jama.279.7.511

Pitt, H., Thomas, S. L., \& Bestman, A. (2016). Initiation, influence, and impact: Adolescents and parents discuss the marketing of gambling products during Australian sporting matches. BMC Public Health, 16(1), 967. doi:10.1186/s12889-016$3610-\mathrm{z}$ 
Pitt, H., Thomas, S. L., Bestman, A., Daube, M., \& Derevensky, J. (2017a). Factors that influence children's gambling attitudes and consumption intentions: Lessons for gambling harm prevention research, policies and advocacy strategies. Harm Reduction Journal, 14(11), 1-12. doi:10.1186/s12954017-0136-3

Pitt, H., Thomas, S. L., Bestman, A., Daube, M., \& Derevensky, J. (2017b). What do children observe and learn from televised sports betting advertisements? A qualitative study among Australian children. Australian and New Zealand Journal of Public Health, 41(6), 604-610. doi:10.1111/17536405.12728

Pitt, H., Thomas, S. L, Bestman, A., Randle, M., \& Daube, M. (2018). Do wagering advertisements contain attention strategies that may appeal to children? An interpretative content analysis. Health Promotion Journal of Australia, 29(3), 265-273. doi:10.1002/hpja.12

Pitt, H., Thomas, S. L., Bestman, A., Stoneham, M., \& Daube, M. (2016). It's just everywhere! Children and parents discuss the marketing of sports wagering in Australia. Australian and New Zealand Journal of Public Health, 40(5), 480-486. doi:10.1111/1753-6405.12564

Pollay, R. W., Siddarth, S., Siegel, M., Haddix, A., Merritt, R. K., Giovino, G. A., \& Eriksen, M. P. (1996). The last straw? Cigarette advertising and realized market shares among youths and adults, 1979-1993. The Journal of Marketing, 60(2), 1-16. doi: $10.2307 / 1251927$

Purdie, N., Matters, G., Hillman, K., Murphy, M., Ozolins, C., \& Millwood, P. (2011). Gambling and young people in Australia. Retrieved from https://www.gamblingresearch.org.au/sites/ default/files/embridge_cache/emshare/original/public/2016/09/ 8e/d7986cb40/youth+report1.pdf

Rossen, F. V., Clark, T., Denny, S. J., Fleming, T. M., Peiris-John, R., Robinson, E., \& Lucassen, M. F. (2016). Unhealthy gambling amongst New Zealand secondary school students: An exploration of risk and protective factors. International Journal of Mental Health and Addiction, 14(1), 95-110. doi:10.1007/s11469-0159562-1

Saffer, H. (2002). Alcohol advertising and youth. Journal of Studies on Alcohol, Supplement, 14, 173-181. doi:10.15288/ jsas.2002.s14.173

Sklar, A., \& Derevensky, J. L. (2010). Way to play: Analyzing gambling ads for their appeal to underage youth. Canadian
Journal of Communication, 35(4), 533. doi:10.22230/cjc. 2010v35n4a2331

Smith, R. E., \& Swinyard, W. R. (1988). Cognitive response to advertising and trial: Belief strength, belief confidence and product curiosity. Journal of Advertising, 17(3), 3-14. doi:10.1080/00913367.1988.10673118

SportsTG. (2018). Girls got game. Retrieved from http://websites. sportstg.com/assoc_page.cgi?c=0-3911-0-0-0\&sID=83061

Sproston, K., Hanley, C., Brook, K., Hing, N., \& Gainsbury, S. (2015). Marketing of sports betting and racing. Victoria, Australia: ORC International. Retrieved from https://www.gamblingresearch. org.au/sites/default/files/embridge_cache/emshare/original/public/ 2016/09/74/bb765bd30/gramarketingofsbandrb.pdf

Thomas, S. L., Bestman, A., Pitt, H., Cassidy, R., McCarthy, S., Nyemcsok, C., Cowlishaw, S., \& Daube, M. (2018). Young people's awareness of the timing and placement of gambling advertising on traditional and social media platforms: A study of 11-16 years olds in Australia. Harm Reduction Journal, 15(1), 51. doi:10.1186/s12954-018-0254-6

Thomas, S. L., Pitt, H., Bestman, A., Randle, M., McCarthy, S., \& Daube, M. (2018). The determinants of gambling normalisation: Causes, consequences and public health responses. Retrieved from https://responsiblegambling.vic.gov.au/resources/ publications/the-determinants-of-gambling-normalisationcauses-consequences-and-public-health-responses-349/

Thomas, S. L., Pitt, H., Bestman, A., Randle, M., Stoneham, M., \& Daube, M. (2016). Child and parent recall of gambling sponsorship in Australia. Retrieved from https://responsible gambling.vic.gov.au/resources/publications/child-and-parentrecall-of-gambling-sponsorship-in-australian-sport-67/

Toscano, N. (2017, September 11). Bookies banned from online sign-up inducements. Sydney Morning Herald. Retrieved from https://www.smh.com.au/business/bookies-banned-fromonline-signup-inducements-20170911-gyewup.html

Victorian Responsible Gambling Foundation. (2018). Time for 'the talk' with your kids...the gambling talk. Retrieved from https://responsiblegambling.vic.gov.au/about-us/news-andmedia/time-talk-your-kids-gambling-talk/

Wigmore, T. (2018, August 6). Football clubs warned over the prevalence of bookmakers sponsoring shirts. The Telegraph. Retrieved from https:/www.telegraph.co.uk/football/2018/08/ 06/football-clubs-warned-prevalence-bookmakers-sponsoringshirts/ 